\title{
Studi Kualitas Semen Ayam Burgo
}

\author{
Heri Dwi Putranto*, Nurmeiliasari, Kendini Tianti Harferry \\ Program Studi Peternakan, Jurusan Peternakan, Fakultas Pertanian, Universitas Bengkulu \\ Jalan W.R. Supratman, Kandang Limun, Bengkulu, 38371 A \\ *Korespondensi : heri_dp@unib.ac.id
}

Artikel ini diterima (received): 3 Desember 2019; dinyatakan disetujui (accepted): 3 Februari 2020; terbit (published): 15 Mei 2020. Artikel ini dipublikasi secara daring pada https://ejournal.unib.ac.id/index.php/buletin_pt

\section{ABSTRAK}

Penelitian ini bertujuan untuk mengevaluasi kualitas semen ayam Burgo untuk tujuan Inseminasi Buatan. Penentuan sampel diambil secara accident sampling. Penelitian ini menggunakan 4 ekor ayam Burgo jantan berumur 12-15 bulan. Pengamatan dilakukan dengan evaluasi semen secara makroskopis terdiri dari volume, bau, warna dan konsistensi. Sedangkan evaluasi secara mikroskopis terdiri dari konsentrasi, gerakan massa, motilitas, dan abnormalitas. Dari pengamatan didapati hasil volume semen $0.21 \mathrm{~mL}$, bau semen ayam Burgo adalah normal seperti bau khas dari ayam itu sendiri, warna semen dan kekentalan yaitu berwarna putih susu dan konsistensi kental. Sedangkan evaluasi secara mikroskopis terdiri dari konsentrasi yaitu $6942 \times 10^{6} \mathrm{spm} / \mathrm{mL}$, Gerakan massa $(+++)$, gerakan individu atau motilitas mendapati angka $84 \%$ dan abnormalitas $8 \%$. Hasil penelitian menunjukkan bahwa semen ayam Burgo mempunyai performa yang baik dan layak untuk digunakan untuk kebutuhan IB.

Kata kunci : Kualitas semen, ayam burgo

\section{PENDAHULUAN}

Ayam lokal tropis perlu dilestarikan agar tidak punah dengan cara peningkatan populasi. Potensi genetik yang sangat berharga dari ayam lokal tropis adalah kemampuan beradaptasi pada lingkungan tropis. Di Indonesia terdapat 31 rumpun ayam lokal yang sangat variatif. Potensi pengembangan ayam lokal tropis telah dilakukan untuk tujuan sebagai ayam hias, petelur dan pedaging.

Ayam lokal unggul di Propinsi Bengkulu adalah ayam Burgo. Ayam Burgo dapat menjadi ayam hias karena bulunya yang indah dan suara yang merdu. Keunggulan lainnya adalah daya tahan tubuh yang baik terhadap penyakit unggas tropis, dan produksi telurnya yang baik. Ayam Burgo yang dipelihara secara tradisional akan menghasilkan telur sebanyak 14 sampai 18 butir per periode bertelur (Warnoto, 2001). Sedangkan ayam Burgo yang dipelihara secara intensif akan mengasilkan telur sebanyak 32,67 butir per periode bertelur (Setianto, 2010). Selanjutnya diketahui ayam telur Burgo betina mempunyai fertilitas yang tinggi yaitu $89,58 \%$. Keunikan fisik ayam ini dapat menjadi model untuk cinderamata bagi wisatawan domestik dan manca negara. Mengingat banyaknya manfaat keberadaan ayam Burgo di Bengkulu maka kelestarian hewan ini sangat penting diperhatikan.

Populasi ayam Burgo di Propinsi Bengkulu hanya $0.23 \%$ dari total populasi ayam kampung populasi ayam Burgo tahun 2013 adalah 275 ekor yang terdiri dari 81 ekor pejantan, 83 ekor indukan dan 111 ekor anakan. Sementara ayam kampung memiliki populasi 121.133 ekor (BPS, 2013). Mencermati hal ini, maka dapat ditarik kesimpulan sementara yaitu minat masyarakat memelihara ayam Burgo masih rendah. Kendala pengembangan ayam Burgo adalah berupa minimnya informasi mengenai reproduksi ayam ini dan populasi yang rendah.

Peningkatan populasi dapat dilakukan dengan kawin alami dan kawin buatan. Perkawinan alam selain memiliki efisiensi reproduksi yang rendah juga memiliki resiko inbreeding. Oleh karena itu perkawinan buatan yaitu melalui metode inseminasi buatan (IB) dapat meningkatkan efisiensi reproduksi dan menghindarkan dari potensi inbreeding. 
Pemeliharaan pejantan memerlukan biaya yang besar . Untuk mengatasi kendala tersebut, salah salah satu alternatif yang dapat dilakukan yaitu dengan penerapan bioteknologi dalam bidang reproduksi ternak dengan melakukan konservasi semen dan penerapan teknologi IB

Keberhasilan IB pada unggas dipengaruhi oleh beberapa faktor antara lain kualitas semen yang digunakan, kebersihan semen yang dikoleksi dan keterampilan inseminator. Diantara faktor tersebut yang memegang peran penting dalam menentukan fertilitas telur adalah kualitas semen (Danang, 2012). Oleh sebab itu, uji kualitas semen ayam Burgo jantan penting dilakukan untuk mengetahui kelayakan semen yang dihasilkan untuk kebutuhan IB. Penelitian ini bertujuan untuk menganalisis kualitas semen ayam Burgo untuk tujuan IB

\section{MATERI DAN METODE \\ Penentuan sampel}

Penentuan sampel diambil secara accident sampling yaitu pengambilan sampel yang dilakukan secara kebetulan, subjek yang dirasa memenuhi syarat berupa volume minimal $0,1 \mathrm{~mL}$, tidak terkontaminasi baik secara warna dan bau.

\section{Pelatihan ayam}

Pelatihan ayam pada metode massage dilakukan selama satu bulan dilakukan setiap 07:00 pagi hingga semen dapat dikoleksi dan memenuhi standar kualitas untuk evaluasi. Hal ini dilakukan ayam terbiasa dengan perlakuan massage dan melatih keterampilan inseminator.

\section{Penampungan semen}

Penampungan semen ayam dilakukan pagi hari jam 08:00 dengan metode pemijatan atau massage pada bagian punggung ayam. Koleksi semen biasanya dilakukan dua orang sebagai penampung dan inseminator (Suprijatna et al., 2005) satu orang memegang ayam dan lainnya melakukan pengurutan dan penampungan semen.

Saat proses massage, tangan membentuk sudut 45 o dengan tulang punggung pejantan dan dilakukan berulang kali sampai pejantan ereksi yang ditandai dengan naiknya bulu ekor dan keluarnya Papillae dari kloaka (Nataamijaya, 2000). Semen yang keluar ditampung pada tabung gelas penampung dipindahkan dalam alat suntik tanpa jarum dan dimasukan dalam termos agar terhindar dari kontaminasi dan ketidaksesuaian suhu, kemudian segera dibawa ke laboratorium untuk di evaluasi. Masing-masing ayam dilakukan satu sampai dua kali pemijatan.

\section{Evaluasi semen}

Semen segar dievaluasi untuk mengetahui kelayakannya untuk digunakan dalam penelitian ini. Evaluasi semen dilakukan dengan 2 cara yaitu pemeriksaan secara makroskopis dan mikroskopis.

\section{Makroskopik}

Pemeriksaan semen secara makroskopis meliputi volume, warna, bau, dan konsistensi.

a) Volume semen

Pemeriksaan volume semen dapat dilakukan dengan melihat skala yang tertera pada tabung penampung semen yang digunakan dalam penelitian ini setidaknya memiliki volume 0,2 - 0,4 /ekor (Toelihere, 1993 ).

b) Warna

Warna dapat dilihat dengan memperhatikan warna semen dan diperhatikan apakah ada kelainan pada semen seperti warna merah akibat kontaminasi darah atau warna hijau akibat kontaminasi kotoran. Warna yang biasanya pada semen yang berkualitas baik adalah warna putih susu.

\section{c) Konsistensi}

Konsistensi semen dapat dilihat dengan memiringkan tabung penampung semen lalu menegakannya kembali. Bila jatuhnya semen lambat maka konsistensinya tinggi semen yang baik adalah dengan konsistensi tinggi atau kental.

d) Bau

Bau yang normal pada semen adalah tidak menyengat, dan tidak ada kontaminasi bau lain seperti darah dan feses (Danang et.al., 2005).

\section{Mikroskopik}

Secara mikroskopis meliputi gerakan massa, konsentrasi, motilitas dan abnormalitas (Hafez, 2000).

a) Konsentrasi

Konsentrasi merupakan jumlah spermatozoa yang terkandung dalam satu $\mathrm{mL}$ ejakulasi. Penilaian konsentrasi penting karena dapat digunakan untuk menentukan jumlah pengenceran semen. spermatozoa yang 
terkandung dalam satu $\mathrm{mL}$ ejakulasi. Penilaian konsentrasi sangat penting karena dapat digunakan untuk menentukan jumlah pengenceran semen. Perhitungan konsentrasi spermatozoa total menggunakan Kamar Hitung Neubauer.

b) Gerakan massa

Gerakan massa dievaluasi dengan cara meneteskan semen di atas gelas objek, diamati di bawah mikroskop pada pembesaran $10 \times 10$, sedangkan kriteria yang dipakai adalah $(+++)$ sangat baik terlihat gelombang-gelombang besar, banyak gelap, tebal, dan aktif seperti gumpalan awan hitam, yang bergerak cepat berpindah-pindah tempat $(++)$ baik; bila terlihat gelombang-gelombang kecil, jarang, tipis, kurang jelas, dan bergerak lamban. $(+)$ sedang, tidak terlihat gelombang melainkan hanya gerakan gerakan individual aktif progresif./s spermatozoa ayam Burgo merupakan perbandingan perkiraan jumlah spermatozoa yang motil dengan jumlah spermatozoa yang terlihat dalam pengamatan. Motilitas spermatozoa dievaluasi dengan cara mencampur satu tetes semen dengan $\mathrm{NaCl}$ fisiologis secukupnya, diletakkan pada gelas objek. Selanjutnya diamati di bawah mikroskop dengan pembesaran $40 \times 10$. Spermatozoa yang begerak dengan baik dibandingkan dengan yang tidak bergerak menghasilkan angka motilitas spermatozoa

Motilitas $=\frac{\sum \text { Sperma bergerak progresif }}{\sum \text { Sperma yang diamati }} \times 100$

c) Abnormalitas spermatozoa

Abnormalitas spermatozoa dihitung dengan mengamati spermatozoa yang normal dan abnormal minimal 200 sel spermatozoa pada sepuluh lapang pandang di bawah mikroskop pembesaran $40 \times 10$, standar minimal abnormalitas $<14 \%$.

\section{Rancangan penelitian}

Penelitian menggunakan semen dari 4 ekor ayam dengan 3 kali ulangan sehingga didapat 12 sampel.

Variabel yang akan diamati dalam menguji kualitas semen yaitu volume, warna, bau, dan konsistensi gerakan massa, konsentrasi, motilitas dan persentase hidup atau mati dan abnormalitas sperma .

Data yang diperoleh dianalisa menggunakan metode deskriptif.

\section{HASIL DAN PEMBAHASAN}

Beberapa studi tentang reproduksi Burgo seperti Perbandingan Frekuensi dan Durasi Perilaku Seksual Berdasarkan Umur pada Pejantan Ayam Burgo. (Putranto et al., 2019), Estradiol- $7 \beta$ hormoneconcentration and follicles number in exotic burgo chicken supplemented by Sauropus androgynus leaves extract (Putranto et al., 2012) telah dilakukan. Artikel ini menjadi evaluasi semen ayam Burgo pertama yang menginformasikan tentang kualitas semen pejantan ayam Burgo dan menjadi standar untuk evaluasi .

Terlihat pada tabel 1 . bahwa ayam $C$ memiliki volume yang paling rendah dilihat dari faktor yang mempengaruhinya dilapangan bahwa ayam $\mathrm{C}$ mempunyai ukuran ttubuh yang lebih kecil disbanding 3 ayam lainnya. Dilihat juga pada ayam $A$ bahwa rata-rata sampel pada ayam A memiliki konsistensi yang encer, gerakan massa dan konsentrasi yang lebih rendah hal ini dikaitkan dengan frekuensi pengkoleksian semen yang lebih tinggi. Hal ini sesuai dengan pernyataan Johari et al. (2009) bahwa volume semen yang dihasilkan tergantung dari bangsa, umur, ukuran badan, nutrisi pakan, frekuensi penampungan dan lainlain

\section{Volume semen}

Volume semen diukur waktu pengambilan semen pada ayam Burgo yang telah dilatih selama satu bulan dengan cara pemijatan. Pejantan yang digunakan dalam penelitian ini yaitu pejantan Ayam Burgo berumur 12-15 bulan. Pemijatan dilakukan pada pukul 07:00 hingga 08:00 pagi. Rataan volume semen ayam burgo dapat dilihat pada Tabel 1.

Pentingnya semen karakteristik semen dalam hal volume dan konsentrasi spermatozoa. Secara alamiah satu ejakulasi semen ayam akan di deposisikan pada satu vagina ayam. Dengan menggunakan teknik IB satu ejakulat dapat diencerkan dan di inseminasikan pada beberapa ekor ayam. Volume semen dan konsentrasi spermatozoa akan menggambarkan kemampuan pejantan yang dapat mengawini ayam betina jika perkawinan dilakukan dengan teknik IB (Setiadi et al., 2019). Hasil penelitan ini sesuai dengan pendapat Getachew (2016) bahwa umumnya kualitas semen ayam lokal mempunyai volume rata-rata antara 0,2 sampai $0,5 \mathrm{~mL}$. 
Tabel 1. Rataan hasil evaluasi emen ayam Burgo

\begin{tabular}{lcccc}
\hline \multirow{2}{*}{ Parameter } & \multicolumn{4}{c}{ Ayam } \\
\cline { 2 - 5 } & A & B & C & D \\
\hline Volume $(\mathrm{mL})$ & 0.21 & 0.2 & 0.16 & 0.21 \\
Warna & Putih susu & Putih susu & Krem & Putih susu \\
Konsistensi & Encer & Kental & Kental & Kental \\
Bau & Normal & Normal & Normal & Normal \\
Gerakan massa & ++ & +++ & +++ & +++ \\
Abnormalitas $(\%)$ & $8 \%$ & $8 \%$ & $8 \%$ & $7 \%$ \\
Motilitas individu $(\%)$ & $88 \%$ & $75 \%$ & $81 \%$ & $82 \%$ \\
Konsetrasi $\left(\times 10^{6} \mathrm{spm} / \mathrm{mL}\right)$ & 7458 & 6800 & 6658 & 6850 \\
\hline
\end{tabular}

Keterangan: (-): buruk; (+): sedang; $(++)$ : baik; $(+++)$ : sangat baik .

Rataan volume semen yang dihasilkan pada ayam Burgo berkisar antara 0,20-0,21 ml. Rata-rata volume semen yang diperoleh lebih tinggi dibandingkan dengan Arab diperoleh jumlah rata-rata volume semen yakni 0,08 hingga $0,09 \mathrm{ml}$ (Pratama, 2011), akan tetapi lebih rendah dari semen ayam yang dilaporkan oleh Toelihere (1985) yaitu berkisar antara 0,3 sampai $1,5 \mathrm{ml}$ per ejakulat. Hasil pengamatan menunjukan bahwa volume semen ayam burgo memenuhi standar IB pada ayam lokal meskipun tidak mencapai hasil yang tinggi ini mengingat ukuran badan ayam Burgo relatif kecil dibanding ayam lokal lainnya.

\section{Warna dan konsistensi}

Warna semen dapat diamati langsung dari tabung penampung semen terbuat dari gelas atau plastik tembus pandang. Warna semen umumnya merupakan indikator kepadatan konsentrasi spermatozoa dalam sekali ejakulasi. Semen unggas domestik bervariasi dari suspensi buram padat hingga cairan encer yang dikeluarkan oleh berbagai kelenjar reproduksi. Itu berkisar dari kepadatan sperma yang relatif tinggi atau derajat yang jelas hingga putih susu, dengan jumlah sperma yang menurun.

Hasil pengamatan warna dan konsistensi semen ayam Burgo menunjukkan rata-rata hasil yang sama yaitu berwarna putih susu dan konsistensi kental. Warna dan konsistensi semen ini menentukan konsentrasi sperma, bila semen kental dan berwarna putih pekat maka konsentrasi sperma tinggi, sebaliknya bila semen encer dan berwarna bening maka konsentrasinya rendah. Dari perbandingan tersebut volume semen ayam burgo memenuhi syarat untuk keperluan IB.

\section{Bau}

Hasil pengamatan dari bau semen ayam Burgo adalah normal pada umumnya memiliki bau amis khas disertai dengan bau khas dari ayam itu sendiri kecuali satu sampel yang terkontaminasi feses yang menunjukkan bahwa semen tersebut normal dan tidak terdapat kontaminasi. Pada umumnya bau semen dikategorikan sebagai bau normal dan pendapat Toelihere (1993) bahwa Bau khas semen disertai dengan bau hewan tersebut. Bau busuk biasa terjadi apabila semen mengandung nanah yang disebabkan oleh adanya infeksi organ

\section{Konsentrasi}

Konsentrasi Sperma ayam Burgo rataan yang didapatkan adalah $4955 \times 10^{6} \mathrm{spm} / \mathrm{ml}$. Pratiwi et al., (2019) menyatakan syarat suatu pengenceran adalah spermatozoa dengan konsentrasi lebih dari $3000 \times 10^{6} \mathrm{spm} / \mathrm{ml}$. Jadi, konsentrasi sperma ayam burgo memenuhi syarat untuk pengenceran dalam keperluan IB. Perbedaan konsentrasi spermatozoa ayam disebabkan oleh faktor pakan, bobot badan, dan jenis. Jenis ayam yang besar umumnya memiliki konsentrasi spermatozoa yang tinggi.

\section{Gerakan massa}

Semen segar yang baru dikoleksi dan belum diencerkan dilakukan pemeriksaan motilitas massa dan individu dengan bantuan mikroskop tanpa menggunakan kaca penutup hal ini dilakukan dengan tujuan dapat terlihat dengan pergerakan spermatozoa jelas tanpa menghambat pergerkan tersebut. Gerakan 
massa sperma merupakan petunjuk derajat keaktifan massa bergerak sperma (indikator tingkat atau persentase aktif) dalam semen.

Gerak massa semen mempunyai kecenderungan untuk bergerak bersama-sama ke suatu arah. Gerakan spermatozoa menunjukkan gelombang yang tebal atau tipis, bergerak cepat atau lambat tergantung dari konsentrasi sperma hidup di dalamnya (Toelihere, 1993).

Dari hasil penelitian ini gerakan massa spermatozoa dari ayam Burgo $66,7 \%$ adalah $(+++)$ sangat baik terlihat gelombanggelombang besar, banyak gelap, tebal, dan aktif seperti gumpalan awan hitam, yang bergerak cepat berpindah-pindah tempat dengan persentase dari 12 sample yang diambil diantaranya $8(+++)$ dan 4 sampel $(++)$. Toelihere (1993) menyatakan gerak massa dengan kriteria $(++)$ adalah baik dimana terlihat gelombang kecil, tipis, jarang, kurang jelas dan bergerak lamban dengan kriteria (++).

Gerakan massa spermatozoa mencerminkan gerakan individu spermatozoa. Semakin aktif dan semakin banyak spermatozoa yang bergerak, maka gerakan massa pun semakin bagus (semakin tebal dan pergerakannya semakin cepat). Lebih jauh dijelaskan bahwa gerakan massa berkisar antara baik sampai dengan sangat baik (+++) . Maka gerakan massa sperma ayam burgo adalah termasuk kriteria baik sampai sangat baik Perbedaan gerakan massa ini disebabkan oleh perbedaan bangsa, umur, kematangan sperma dan plasma semen.

\section{Gerakan individu spermatozoa}

Motilitas merupakan daya gerak individu sperma yang digunakan sebagai ukuran kemampuan sperma untuk membuahi sel telur. Daya gerak maju ini sangat diperlukan pada saat berada di dalam saluran kelamin betina untuk mencapai tempat terjadinya fertilisasi (Danang et al., 2012). Pengujian motilitas spermatozoa merupakan satu parameter penting (patokan) yang dapat dijadikan dasar informasi penilaian untuk IB.

Rataan motilitas yang didapat pada penelitian ini yakni 71-84\%,. Getachew (2016) melaporkan umumnya kualitas semen ayam lokal mempunyai volume rata-rata motilitas sebesar 60 sampai $80 \%$. Jadi, dapat dilihat bahwa ,motilitas sperma ayam burgo pada penelitian ini dapat memenuhi standar motilitas dalam kualitas semen untuk keperluan IB dalam standar motilitas sperma.

\section{Abnormalitas spermatozoa}

Penentuan jumlah dan macam Abnormalitas spermatozoa di dalam suatu ejakulat harus dipakai secara bersamaan dengan pemeriksaan-pemeriksaan lain yang dilakukan segera setelah penampungan semen seperti penentuan motilitas, konsentrasi dan jumlah spermatozoa hidup dan mati (Toelihere, 1993). Sel spermatozoa yang normal terdiri dari kepala, leher bagian tengah (badan) dan ekor yang tidak menyimpang. Beberapa bentuk penyimpangan dari morfologi dianggap abnormalitas, antara lain, sel spermatozoa dengan kepala raksasa atau kerdil, kepala rangkap,ekor melingkar, spermatozoa tanpa kepala atau ekor.

Bentuk abnormalitas yang ditemukan selama penelitian rata-rata adalah abnormalitas tersier, yang berbentuk ekor melingkar dan kepala membesar. Bentuk abnormal ini menunjukaan bahwa abnormal tersebut disebabkan oleh faktor lingkungan, pada penyimpanan yang dilakukan.

Abnormalitas primer terjadi pada testis saat proses spermatogenesis tepatnya di tubuli semiferi. Abnormalitas primer ditandai oleh kepala yang terlampau kecil (microcephalic) atau terlalu besar (macrocephalic), kepala yang lebar, ekor atau badan berganda. Abnormalitas sekunder terjadi di epididymis sewaktu ejakulasi. Rataan persentase abnormalitas penelitian ini adalah $8 \%$.

\section{KESIMPULAN}

Berdasarkan hasil dari penelitian yang telah dilakukan maka didapati bahwa hasil pengamatan secara makroskopis yaitu volume mempunyai rataan volume $0.21 \mathrm{ml}$, bau semen ayam Burgo adalah normal seperti bau dari ayam itu sendiri, warna semen dan kekentalan menunjukan hasil yang sangat baik yaitu berwarna putih susu dan konsistensi kental. Sedangkan evaluasi secara mikroskopis terdiri dari Konsentrasi yaitu $4955 \times 10^{6} \mathrm{spm} / \mathrm{ml}$, Gerakan massa (+++) yang berarti mempunyai gerakan massa yang sangat baik, begitu pula dengan gerakan individu atau motilitas mendapati angka 84\% dan abnormalitas yang rendah yaitu $8 \%$. Dari hasil tersebut dapat disimpulkan bahwa semen ayam Burgo 
mempunyai kualitas yang baik dan layak untuk digunakan dalam kebutuhan IB.

\section{UCAPAN TERIMA KASIH}

Penelitian ini merupakan bagian dari kegiatan Hibah Penelitian Berbasis Kompetensi yang didanai oleh Direktorat Jenderal Penguatan Riset dan Pengembangan (DRPM) Kementerian Riset Teknologi dan Pendidikan Tinggi Republik Indonesia dengan nomor kontrak: 534/UN30.15/LT/2018.

\section{DAFTAR PUSTAKA}

BPS. 2013. Statidtik Indonesia 2013. Badan Pusat Statistik. Jakartam Indonesia.

Danang I.N. 2012. Pengaruh lama simpan spermatozoa terhadap kualitas spermatozoa ayam kampung dalam pengencer ringer's pada suhu 4 으. Jurnal Ternak Tropika, 13: 47-57.

Gethachew, T. 2016. A review article of artificial insemination in poultry. Veterinary Journal World Vet Journal, 26-35

Hafez, E. 2000. Preservation and cryopreservation of gametes and embryos in Reproduction in Farm Animals. Ed ke-7. Lippincott Williams \& Wilkins, Philadelphia, pp. 431- 442.

Johari, S., Y.S. Ondho, S. Wuwuh, Y.B. Henry dan Ratnaningrum. 2009. Karakteristik dan kualitas semen berbagai galur ayam Kedu. Fakultas Peternakan Universitas Diponegoro. Diseminarkan dalam Seminar Nasional Kebangkitan Peternakan pada tanggal 20 Mei 2009 di Semarang.

Nataamijaya A.G.A.S.R. 2000. Kuantitas dan kualitas spermatozoa ayam kampung dan Arab yang mendapat suplemen vitamin $E$ ( $\alpha$-Tocopherol), Jurnal Produksi Ternak 7: 74-80.
Pratama, G. 2011. Karakteristik semen ayam Arab pada frekuensi penampungan yang berbeda. Bogor. Skripsi. Fakultas Peternakan, Institut Pertanian Bogor.

Pratiwi, N., T.L. Yusuf, I. Arifiantini dan C. Sumantri. 2019. Kualitas spermatozoa dalam modifikasi pengencer . Acta Veterinaria Indonesiana, 7: 46-54.

Putranto, H.D, J. Setianto, dan U. Santoso. 2012a. Estradiol- 7ß hormoneconcentration and follicles number in exotic burgo chicken supplemented by Sauropus androgynus leaves extract.Biodiversitas, 13 (1) : 1-6.

Putranto H.D, J. Setianto, Y. Yumiati, dan E. Nurandriyanto. 2019 . Perbandingan frekuensi dan durasi perilaku seksual berdasarkan umur pada pejantan ayam Burgo. Jurnal Sain Peternakan Indonesia, 14: $38-48$

Setiadi, D.R., H. Hasibuan, R. Indriastuti, dan A.A. Arif. 2019. Karateristik ayam IPB D-1. BOGOR: Fakultas Kedokteran Hewan, Institut Pertanian Bogor.

Setianto, J., and Warnoto. 2010. The Phenotype characteristic, population and enviroment of Bengkulu's Burgo chicken. Dalam Presented on international seminar "The Role and Aplication of Biotechnology on Livestock. Bukittinggi, West sumatra.

Suprijatna, E., U. Atmomarsono dan R. Kartasudadjana. 2005. Jakarta : Ilmu Dasar Tenak Unggas. Cetakan 1. Penebar Swadaya, Jakarta.

Toelihere, M.R. 1993. Inseminasi Buatan pada Ternak. CV Angkasa. Bandung.

Warnoto. 2001. Analisis poduksi telur ayam Burgo yang dipesihara secara tradisonal di Bengkulu. Laporan Penelitian Unin Due Like Award. Universitas Bengkulu. UNIB. 